\section{Species richness and the energy theory}

SIR-I wish to point out some fundamental flaws in the data analysed by Turner et al. in their recent letter ${ }^{1}$.

One difficulty with the study of the distribution of birds compared with other groups is that they are very highly mobile, and individual populations of the same species often react differently to changing seasons. The abundance and spread of several species also depends on population levels in the previous season, whether winter or summer. Several of the so-called resident species used in the analysis are by no means sedentary, and one, the bearded tit, is not insectivorous in winter. By definition, maps $a$ and $c$ in their Fig. 1 should at least show a similarity in distribution, or even a reversal of that shown, with many inland breeders moving coastwards for the winter.

The quoted winter surveys of 1981-84 were quantitative ${ }^{2}$, and recorded a species present even if only one individual was observed during the three winters. These data can hardly be statistically valid in such an analysis. Four of the six winter visitors are very scarce, and would not be expected to show a representative distribution. Two (woodlark and black redstart) also breed, although the origin of the wintering birds is not clear. Furthermore, chiffchaffs do not show an urban winter distribution. Indeed, small insectivorous visitors to Britain in winter are neither widespread nor numerous. I also cannot understand the choice of habitats used in the analysis. It is not surprising that there is little correlation with species distribution. For the five types of natural habitat entered into the regression, nine of the resident species normally occupy none, and a further nine occupy only one.

Two other errors in the letter concern statements on cold weather and sunshine. First, the statement that cold weather kills birds is too simplistic. It is unusual for this to be a direct cause of death, and then only when temperatures persistently fall well below the normal variation found in a species' environment. In most cases a bird will survive cold weather as long as sufficient food remains available, and it is the sudden and marked reduction in food supplies due to hard frost, ice and snowcover that causes widespread mortality, not the effect of low temperature itself.

Second, in a review on the responses of birds to sunshine and high temperatures ${ }^{3}$, I showed that feather conditioning is only one of several reactions. Sunning in birds is also thought to be undertaken for the manufacture of vitamin D, to enable ectoparasites to be removed more easily, and simply to warm the body. Thermoregulation may well be the more important function of sunbathing ${ }^{4}$.

In view of the points raised above, I remain sceptical of the authors' conclusions.
I am not convinced that there is any direct relationship between species richness and solar energy. This energy is, however, directly responsible for the distribution and abundance of vegetation and associated animal prey which provide nesting habitat and food for avian populations, that is, the habitat theory refuted by the authors, and that proposed by Wright ${ }^{5}$, who related species richness to total net primary production and not merely climatic variables.

\section{Scotstanit View,}

NORMAN ELKINS

Cupar,

Fife, KY15 4DX, UK

SIR-Recent suggestions ${ }^{1,5,6}$ that available energy, rather than other candidate causes $^{7}$, predominantly explains latitudinal gradients of species richness need further clarification on the form such an energy theory might take. This can be illustrated by commenting on the recent paper of Turner et al. ${ }^{1}$.

If the change in energy availability with latitude is the cause of the change in species number, then it is a prerequisite that such a change is mediated by change in the number of individual organisms. With less energy available, the numbers of individuals of all species might be reduced leading to zero members in some species. Members of different taxa are not equivalent in their energy demands ${ }^{1}$. But important differences also occur within taxa, for example, between bird species of different sizes. The replacement of large bird species by small birds species could increase diversity under conditions of reduced energy input. Thus, any 'energy theory' of species diversity needs to take into account that it is the numbers of individuals of different body sizes that are causally affected by any energy limitation. The relationship between the numbers of individuals of different sizes and the numbers of species is central to any energetics explanation of species diversity. Hutchinson ${ }^{8}$ suggested that latitudinal gradients in species number are caused by gradients in numbers of individuals which in turn are caused by gradients in solar energy input, the relationship possibly being mediated by body size'.

To test the relationship between body-size distributions of individuals and species in a community I examined 85 common bird census units (average 40 hectares $\left(4 \times 10^{5} \mathrm{~m}^{2}\right)$ each $)$. The $\mathrm{CBC}^{10}$ records the abundance of all breeding bird species using species-specific techniques for mapping breeding populations. Of the 85 data sets, five had equal species and individual medians, 41 had species medians greater than individuals, for 39 the reverse was true; a $\chi^{2}$ test $\left(v=84, \chi^{2}=77.8\right)$ indicated no evidence of difference between expected equal distribution of species and individual medians; Spearman's rank correlation for individual and species medians $(r=0.70 P<0.001)$. If the median species weight and median individual weight in a community is closely correlated then this would establish an empirical link between diversity and energetics phenomena.

Body size is the subject of biogeographical study as Bergman's rule which can be applied to between and within species variation ${ }^{11}$. Body size has also assumed an important role in explaining trophic structure, that is, how energy flows through a food web $b^{12,13}$. The study of spatial distribution of body size therefore offers an integrating perspective to a biogeography based on energetic principles. Using data for British breeding birds ${ }^{14}$, the figure shows species with larger body size to be found at higher altitudes and

\begin{tabular}{|c|c|c|c|c|c|}
\hline & Latitude & Altitude & January ${ }^{\circ} \mathrm{C}$ & July ${ }^{\circ} \mathrm{C}$ & Rainfall \\
\hline \multicolumn{6}{|l|}{ All land species } \\
\hline$S$ per $2,500 \mathrm{~km}^{2}$ & $-0.31 *$ & $0.08 \mathrm{NS}$ & 0.07 NS & $0.10 \mathrm{NS}$ & $0.10 \mathrm{NS}$ \\
\hline Mean weight & $0.75^{* *}$ & $0.86 * *$ & $-0.75^{* *}$ & $-0.91 * *$ & $0.75 * *$ \\
\hline Median weight & $0.69 * *$ & $0.74 * *$ & $-0.71 * *$ & $-0.81^{* *}$ & $0.57^{* *}$ \\
\hline \multicolumn{6}{|l|}{ Resident species } \\
\hline$S$ per $2,500 \mathrm{~km}^{2}$ & $0.14 \mathrm{NS}$ & $0.49 * *$ & $-0.32 *$ & $-0.36 * *$ & $0.39 * *$ \\
\hline Mean weight & $0.75^{* *}$ & $0.87^{* *}$ & $-0.73^{* *}$ & $-0.91 * *$ & $0.76 * *$ \\
\hline Median weight & $0.78 * *$ & $0.80^{* *}$ & $-0.75^{* *}$ & $-0.86 * *$ & $0.62 * *$ \\
\hline \multicolumn{6}{|l|}{$\begin{array}{l}\text { Summer migrant } \\
\text { species }\end{array}$} \\
\hline$S$ per $2,500 \mathrm{~km}^{2}$ & $-0.74 * *$ & $-0.52 * *$ & $0.58 * *$ & $0.67 * *$ & $-0.38 * *$ \\
\hline Mean weight & $-0.32 * *$ & $-0.17 \mathrm{NS}$ & $0.15 \mathrm{NS}$ & $0.24 \mathrm{NS}$ & -0.05 NS \\
\hline Median weight & $-0.49 * *$ & $-0.29 *$ & $0.34 * *$ & $0.42 * *$ & $-0.19 \mathrm{NS}$ \\
\hline \multicolumn{6}{|c|}{ Environmental variabies } \\
\hline Rainfall per year & $-0.37^{* *}$ & $0.82 * *$ & $0.11 \mathrm{NS}$ & $-0.60 * *$ & 1.00 \\
\hline July ${ }^{\circ} \mathrm{C}$ & $-0.91 * *$ & $-0.77 * *$ & $0.86 * *$ & 1.00 & \\
\hline January ${ }^{\circ} \mathrm{C}$ & $-0.70^{* *}$ & $-0.28 *$ & 1.00 & & \\
\hline Altitude & $0.69 * *$ & 1.00 & & & \\
\hline Latitude & 1.00 & & & & \\
\hline
\end{tabular}

The number of species, $S$, found in each of the 90 areas shown in the figure, the mean and the median weight of the set of species in each area were correlated using Spearman's rank coefficient $(* P<0.01$, $* * P<0.001$ ) with environmental data from overlay maps ${ }^{14}$. January and July temperatures at sea level are adjusted by $-0.6^{\circ} \mathrm{C}$ per $100 \mathrm{~m}$ to surface temperature predicted from altitude overlay. NS, not significant. 